\title{
Marco Polo, Le devisement du monde, tome V, À travers la Chine du Sud - tome VI et dernier, Livre d'Ynde. Retour vers l'Occident
}

\section{G. Matteo Roccati}

\section{(2) OpenEdition}

Journals

Édition électronique

URL : http://journals.openedition.org/studifrancesi/5866

DOI : $10.4000 /$ studifrancesi.5866

ISSN : 2421-5856

Éditeur

Rosenberg \& Sellier

Édition imprimée

Date de publication : 1 mai 2011

Pagination : 147

ISSN : 0039-2944

\section{Référence électronique}

G. Matteo Roccati, « Marco Polo, Le devisement du monde, tome V, À travers la Chine du Sud - tome VI et dernier, Livre d'Ynde. Retour vers l'Occident », Studi Francesi [En ligne], 163 (LV | I) | 2011, mis en ligne le 30 novembre 2015, consulté le 13 janvier 2021. URL : http://journals.openedition.org/studifrancesi/ 5866 ; DOI : https://doi.org/10.4000/studifrancesi.5866

Ce document a été généré automatiquement le 13 janvier 2021.

\section{cc) (†) $\odot$}

Studi Francesi è distribuita con Licenza Creative Commons Attribuzione - Non commerciale - Non opere derivate 4.0 Internazionale. 


\title{
Marco Polo, Le devisement du monde, tome V, À travers la Chine du Sud - tome VI et dernier, Livre d'Ynde. Retour vers l'Occident
}

\author{
G. Matteo Roccati
}

\section{RÉFÉRENCE}

MARCo POLO, Le devisement du monde, Édition critique publiée sous la direction de Philippe MÉNARD, tome V, À travers la Chine du Sud, édité par Jean-Claude DELCLos et Claude RouSSEL, Genève, Librairie Droz, 2006 («Textes littéraires français», 586), pp. 304. MARCo polo, Le devisement du monde, Édition critique publiée sous la direction de Philippe MÉNARD, tome VI et dernier, Livre d'Ynde. Retour vers l'Occident, édité par Dominique BOUTET, Thierry DELCOURT, Danièle JAMES-RAOUL, Genève, Librairie Droz, 2009 («Textes littéraires français», 597), pp. CXXXVIII-406.

1 Suite et fin de l'édition collective de la version française (voir Rassegna, t. XLVII, n. 140, pp. 415-416; t. XLVIII, n. 144, p. 581; t. L, n. 150, p. 576). Le tome V (ch. 138-156) achève la description de l'Empire du Milieu, en rassemblant dans un discours ordonné des matériaux relatifs sans doute à plusieurs voyages dans la Chine du Sud. Le tome VI (ch. 157-194) relate les étapes du retour - Indonésie, Inde, le récit s'arrête à Hormuz - en intégrant des souvenirs de voyages antérieurs et des renseignements et légendes obtenus de marins chinois et arabes. L'ouvrage est inachevé et il n'est pas question du voyage de la Perse à Venise.

2 Comme dans les quatre premiers tomes, l'introduction s'appuie sur la partie du texte éditée pour traiter de la tradition manuscrite et de la langue du manuscrit de base (Londres, BL, Royal 19 D 1 (B1), se terminant au ch. 194; quatre chapitres sont ensuite ajoutés d'après la famille $\mathrm{A}$ pour donner l'ensemble de la version française, mais 
l'édition ne va pas au-delà et reste fidèle à cette version, dont la fin est écourtée et qui s'achève par le récit des combats des chefs mongols). Elle analyse aussi le contenu et les traits marquants de la partie de texte objet du volume, et fournit une bibliographie sélective (en fait assez étendue). L'édition indique les leçons rejetées en bas de page; elle est suivie des notes, des variantes, de l'index des noms propres, du glossaire et des illustrations (reproductions et cartes).

Dans le tome $\mathrm{V}$ une annexe détaille l'Itinéraire adopté par Marco Polo pour la présentation de la province du «Mangy», dans le tome VI on trouvera enfin des Addenda et Corrigenda aux cinq premiers tomes (pp. 357-371). 